\title{
Neoliberalismo em tempos de coronavírus ou coronavírus em tempos de neoliberalismo?
}

Bruna Soloina Monteiro Machado, Marcos Vinícius Fernandes Gonçalves e Maria Fernanda Gomes Arcanjo

\section{Q OpenEdition \\ 1 Journals}

Edição electrónica

URL: http://journals.openedition.org/espacoeconomia/12379

ISSN: 2317-7837

Editora

Núcleo de Pesquisa Espaço \& Economia

Refêrencia eletrónica

Bruna Soloina Monteiro Machado, Marcos Vinícius Fernandes Gonçalves e Maria Fernanda Gomes Arcanjo, « Neoliberalismo em tempos de coronavírus ou coronavírus em tempos de neoliberalismo? », Espaço e Economia [Online], 18 | 2020, posto online no dia 18 abril 2020, consultado o 23 setembro 2020. URL : http://journals.openedition.org/espacoeconomia/12379

Este documento foi criado de forma automática no dia 23 setembro 2020.

(C) NUPEE 


\section{Neoliberalismo em tempos de coronavírus ou coronavírus em tempos de neoliberalismo?}

Bruna Soloina Monteiro Machado, Marcos Vinícius Fernandes Gonçalves e Maria Fernanda Gomes Arcanjo

1 Resenha de: DAVIS, Mike, et al. Coronavírus e a luta de classes. Terra sem Amos: Brasil, 2020. Disponível em: https://terrasemamos.files.wordpress.com/2020/03/ coronavc3adrus-e-a-luta-de-classes-tsa.pdf.

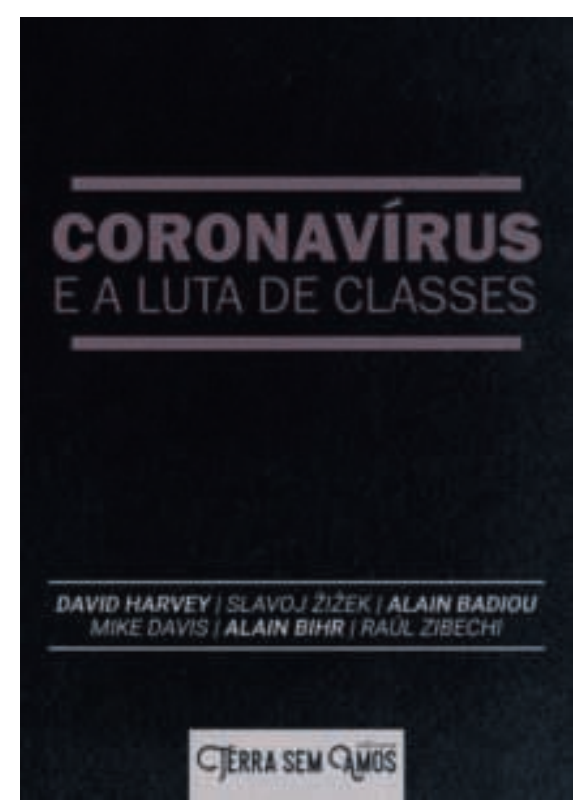

2 Em meio ao colapso da saúde global uma reflexão sobre a hierarquia social decorrente do sistema econômico vigente é necessária, visto que, apesar do contágio da COVID-19 ser democrático, as ações para superá-lo não são; muito menos a intensidade que irá atingir cada país e indivíduo. O modelo capitalista dos últimos anos proporcionou uma estrutura global na qual o poder privado atua diretamente sobre as decisões políticas, 
resultando na mercadorização de elementos essenciais, como, por exemplo, o direito à saúde. No momento atual de crise sanitária e econômica, as consequências das farsas neoliberalistas afloram dentre tantos problemas.

Diante desse cenário, a Editora Terra Sem Amos reuniu artigos que vão da América Latina à Europa, assinados por seis autores, no livro "Coronavírus e a Luta de Classes". Disponível nas versões física e gratuitamente on-line, a obra conta com as publicações traduzidas de Alain Badiou, Alain Birh, Mike Davis, David Harvey, Raúl Zibechi e Slavoj Zizek, os quais desenvolvem suas críticas individuais acerca do eminente vírus, unidos pela preocupação com a questão social.

4 Após a publicação original dos artigos mencionados, a Organização Mundial da Saúde (OMS) caracterizou a doença causada pelo coronavírus como pandêmica, já que sua disseminação geográfica se deu mais rápido que o esperado e as medidas tomadas pelos governos federais deveriam ser ainda mais rigorosas. Contudo, alguns países - como o Brasil - seguiram duvidando da pandemia, enquanto outros ainda não conseguiram respostas perante ao vírus, o que tem proporcionado muitas reflexões em todo o mundo.

5 Dessa forma, as análises levantadas pelos autores questionam as ações de governos federais e locais para com a sociedade e como a ideologia neoliberal vigente nos levou a esse estado de crise. A aguda divisão de classes, tal como as políticas estritamente internas de cada país, elucidam o embate entre eficiência e precarização. Isto é, como as políticas público-privadas atuais impossibilitam o acesso das minorias à serviços básicos de sobrevivência, os quais deveriam ser um direito.

6 A seguir, a nossa resenha propõe uma análise de cada um dos seis textos a fim de contribuir para o debate teórico proposto pelos autores e dessa maneira continuar a reflexão sobre o tema. Afinal, seria este o momento de pensar em uma reorganização da economia global?

\section{A crise do coronavírus é um monstro alimentado pelo capitalismo, por Mike Davis}

7 Mike Davis, importante teórico urbano e autor de "O monstro bate à nossa porta: a ameaça global da gripe aviária" (Rio de Janeiro: Record, 2006 [2005]), em sua análise sobre o coronavírus, expõe as dificuldades enfrentadas pela comunidade científica no que concerne à falta de informações precisas sobre os impactos do vírus e a obscuridade dos números. Além da questão biológica, como a mutação e contágio, obstáculos são encontrados quanto às questões sociais, econômicas e políticas: desnutrição, desemprego, desinvestimento na saúde pública, inflação e um sistema financeiro instável. $\mathrm{O}$ autor destaca principalmente como as coalizões políticas entre o público e o privado em forma de entidades com e sem fins lucrativos impactam direta e negativamente na pandemia, impedindo o desenvolvimento de um sistema de saúde público de qualidade. Além disso, Davis propõe medidas a serem tomadas pelos políticos e movimentos sociais progressistas, a fim de minimizar os impactos da pandemia com uma solidariedade internacional aos países pobres: "defender a propriedade social e a democratização do poder econômico" (p. 12).

8 O autor utiliza como exemplo para comprovar sua tese, a necropolítica da indústria dos asilos norte-americanos que expõe a contradição: tais ambientes em sua maioria são 
privatizados e subfinanciados, e mesmo assim possuem instalações muito precárias, ocasionando na morte consentida de milhares por ano. Estes locais foram apontados como epicentro da doença, onde o vírus se disseminou de maneira rápida e sem controle pela demora de ação do isolamento por parte do governo. Essa realidade demonstra com clareza a divisão de classes americana expressa no acesso à saúde de emergência, onde boa parte da população precisa escolher entre a renda para sobrevivência ou proteção ao vírus, ficando às margens de quaisquer medidas assistencialistas, que deveriam ser um direito de todo indivíduo. $O$ caso brasileiro não fica distante do exposto acima: a relação público-privada na configuração da política de assistência à saúde nos anos de implementação do Sistema Único de Saúde (SUS) e o próprio sucateamento e limite de atendimento das instalações hospitalares governamentais traçam um cenário nacional de fragilidade na economia e dilaceração na saúde pública diante da calamidade epidêmica. E este é o momento no qual as divisões de classe se manifestam com mais clareza.

9 Sem um plano que sirva de exemplo ideal, as ações do governo atual perante a crise estão sendo centralizadas somente para retomada econômica, ponto em risco a saúde nacional diante de uma crise viral, a qual não se tem certeza sobre a dimensão, dentro de um país com tamanha desigualdade e carências.

10 A impotência mundial perante o vírus é resultante dos vários anos de desinvestimento em necessidades básicas, principalmente na saúde. A lógica neoliberal que prevalece nas indústrias farmacêuticas impede qualquer medida efetiva e concreta - como o surgimento de antivirais, uma vez que não são lucrativas o suficiente para serem financiadas. O mercado financeiro mundial, o qual é totalmente dependente da globalização, já estava sob aviso de uma possível crise desde 2008. Todavia, mesmo assim, devido à carência de uma infraestrutura universal de saúde que vá para além dos interesses capitalistas, está em um momento de pleno risco econômico, biológico e social dentro da eminente epidemia.

\section{Política anticapitalista em tempos de covid-19, por David Harvey}

11 O geógrafo britânico David Harvey, para iniciar sua tese, propõe enxergar o capitalismo global sob a égide de duas concepções marxistas: as contradições da circulação e acumulação do capital e a reprodução social numa relação metabólica com as naturezas. Ele define o sistema como um espiral, uma vez que os "momentos" de acumulação são cíclicos: se repetem e renovam através da reestruturação econômicareinvestimento. A partir disso, ressalta como as epidemias são mais influenciadas por ações econômicas do que propriamente naturais, como a mutação. Pode-se dizer que a COVID-19 é um problema mais político do que biológico, quando analisado a partir da relação metabólica que Harvey e Davis trazem ao debate. Ou seja, o próprio modelo econômico hegemônico com suas contradições e fissuras, desenha os rumos geográficos de um vírus no mundo, que atinge os indivíduos e países de maneiras muito disformes. Harvey aponta a epidemia como de classe, gênero e raça (p. 21), algo bastante nítido no Brasil, uma vez que o Ministério da Saúde nacional publicou uma pesquisa comprovando a maior letalidade por COVID-19 na população negra ( 1 a cada 3 mortos) ${ }^{1}$.

Harvey e Davis possuem retóricas muito semelhantes quando aborda, por exemplo, as coalizões políticas na saúde das últimas décadas como a raiz de grande parte dos problemas relacionados a epidemia. A doença se tornou uma prática muito lucrativa 
para as indústrias farmacêuticas, e nesse modelo de negócio, quanto pior o doente esteja, melhor para a lógica empresarial. Ou seja, o investimento em hospitais, pesquisas científicas e um sistema público de saúde é quase nulo em países com políticas neoliberais. Porém, frente à atual epidemia, estes se vêm em situações perigosas: têm se mostrado muito menos prevenidos e aptos para enfrentar as dificuldades de uma crise sanitária como a da COVID-19 e se revelado profundamente dependentes da China para o fornecimento de equipamentos básicos de saúde. No sistema hegemônico, a base da economia é o consumismo instantâneo, o qual já apontava sinais de declínio- os indivíduos estão comprando cada vez mais somente o necessário. No momento de isolamento social, a estrutura neoliberal que se tem é posta toda em risco de profundas mudanças e por que não, superações. Assim, segundo Harvey, "se eu quisesse ser antropomórfico e metafórico sobre isso, concluiria que a COVID-19 é a vingança da natureza por mais de quarenta anos de maus-tratos grosseiros e abusivos da natureza sob a tutela de um extrativismo neoliberal violento e desregulado" (p. 18).

13 A economia global sofre o pior choque desde a Grande Depressão, quando o PIB mundial caiu cerca de $15 \%$, além do estrangulamento do sistema de saúde global ${ }^{2}$. As entidades empresariais vêm atuando no direcionamento da política nacional de saúde buscando ampliar sua organização política em todo o mundo, mas em situação de calamidade ficam dependentes de ações governamentais para se manterem no sistema, mostrandonos a fragilidade do neoliberalismo. A eminência da COVID-19 trouxe à tona uma questão contraditória na geopolítica capitalista: sem possibilidade de contar com a China, os Estados Unidos precisarão agir com políticas mais voltadas ao socialismo para tentar equilibrar a economia em crise, diante de tamanha recessão econômica.

\section{França: pela socialização do aparato de saúde, por Alain Bihr} um "capital de saúde" e, que numa concepção de mundo social individualista que abrange a política neoliberal, bastaria, portanto, que cada indivíduo cuidasse de sua própria saúde. Porém, a excepcionalidade da pandemia escancara o que, em condições normais, seria encoberto. Isto é, o estado de saúde de cada pessoa depende do estado de saúde do corpo social. Nesse sentido, as condições insalubres e desgastantes de trabalho, poluição do ar e da água, a junk food, etc., constituem fatores, que gerados pela indústria capitalista e ignorados pela ideologia neoliberal, ajudam a deteriorar cotidianamente a saúde geral da população. Soma-se a isso o fato de que os hospitais públicos são vítimas de estrangulamento financeiro anos após anos e a constatação de que a medicina liberal está pouco interessada na saúde geral da população, pois esta é vista como um negócio, e como tal, o objetivo final é gerar lucro - o autor cita por exemplo a prática dos hospitais privados de enviar os casos mais graves e mais custosos a hospitais públicos. Apesar de o autor tecer essas considerações levando em conta o contexto político da França, essas reflexões se aplicam à realidade de muitos países mundo afora e sobretudo ao contexto brasileiro: basta recordar da emenda do teto de gastos públicos, aprovada em 2016, que limitou as despesas públicas por 20 anos, incluindo os gastos em saúde ${ }^{3}$.

Num contexto de pandemia global, os governos nacionais tomam medidas de isolamento social que acabam por suprimir liberdades individuais e, 
consequentemente, o discurso neoliberal que exalta as capacidades individuais do autocuidado. No trecho a seguir o autor resume sua tese:

"Este é o fim da exaltação implícita da liberdade de escolha de cada indivíduo quanto à sua estratégia para desenvolver o seu capital de saúde! Ao confinar cada um nas suas próprias casas e, consequentemente, ao restringir sua liberdade de circulação, bem como todas as liberdades públicas em geral, estas autoridades reconhecem implicitamente que a saúde é, acima de tudo, um bem público, que precisa ser preservado como tal." (p. 27).

Ao final do texto, o autor lista algumas propostas direcionadas ao poder público da França, dentre as quais, destacamos o financiamento de medidas urgentes através de um imposto sobre grandes fortunas, a suspensão de quaisquer medidas de sucateamento dos serviços públicos de saúde e a nacionalização de grupos farmacêuticos que não priorizem em seus programas de pesquisa e desenvolvimento a saúde pública.

\section{Coronavírus: a militarização das crises, por Raúl Zibechi}

Raul Zibechi, jornalista e analista político uruguaio, contrapõe os demais autores ao fazer uma análise minuciosa sobre os métodos no qual o governo chinês opera para superar a crise causada pelo coronavírus, uma vez que para o pensador o monitoramento extremo da população chinesa é mascarado através das medidas de proteção para a epidemia. De fato, perto de se tornar o novo hegemon do sistema internacional, a China investe intensamente em seu modelo de sociedade em vigilância, podendo ser equiparada, neste sentido, com a Alemanha nazista e a União Soviética estalinista. A cidade de Wuhan - foco dos primeiros casos da COVID-19 - é exemplo de tal monitoramento, visto que o direito de circular é dado apenas aos profissionais da área de saúde, ou seja, as pessoas, mesmo saudáveis, estão vivendo em função do medo.

O jornalista latino-americano usa como referência o boletim do Laboratório Europeu de Antecipação Política (LEAP) para evidenciar que a tendência de poder, promovida pelo polo hegemônico chinês, já é aceita pelo Ocidente como uma nova forma de gerir crises, uma vez que a Itália com apenas dezesseis casos isola grande parte da população. Ao mesmo tempo, o modelo é apoderado pelos próprios habitantes, dado que os confinamentos se tornaram voluntários. Para finalizar a abordagem social sobre a epidemia, o autor faz três apontamentos com embasamento nos movimentos antissistêmicos: [1] O modelo de controle social que a China apresenta ao mundo, desperta o interesse de qualquer classe dominante - inclusive a capitalista - que deseja manter os de baixo na linha; [2] As medidas de segurança usadas na epidemia criam o que o autor nomeia de "grandes laboratórios de engenharia social", onde a vigilância vai do macro ao micro, isto é, das ruas à censura na online; [3] por fim, há uma reflexão sobre a perplexidade em enfrentar esta tecnologia que domina a sociedade e vai de encontro com sua militarização. Combinadas, as considerações levantadas revelam que o controle populacional será aplicado em muitas situações futuras.

\section{Sobre a situação epidêmica, por Alain Badiou}

20 O filósofo marroquino Alain Badiou inicia o seu texto criticando a reação geral à pandemia, que ele julga infestada de "lamentos duvidosos e tolices revoltantes" (p. 35). 
A atuação das redes sociais é particularmente destacada, pois estas desempenhariam um papel de propagação de rumores descontrolados (ou no vocabulário da mídia, "fake news") e, nas palavras do autor, do "obscurantismo fascista" (p. 42). Por isso, o autor explica que, em primeiro lugar, a pandemia não foi totalmente inesperada e que, diante disso e de um desprezo pela simplicidade, algumas considerações elementares têm sido ignoradas. Logo, o autor trata de examiná-las.

Badiou lembra que a pandemia expõe o atual estágio de conexão planetária que o mundo se encontra. Mesmo que a China - país central para a economia mundial - tenha se esforçado para diminuir a difusão do vírus, o mercado encontra-se globalizado de tal maneira que as tentativas de frear a difusão para outros países demonstraram-se falhas praticamente no mundo todo. Talvez isso fosse mesmo inevitável dada à necessidade de mobilidade incessante do capitalismo atual. $O$ autor, então, toca numa contradição importante: ainda que a economia esteja sob a égide do mercado mundial, os poderes políticos, por outro lado, permanecem "essencialmente nacionais". A metáfora da guerra, adotada por diversas autoridades políticas, e na França, por Macron, impõe aos Estados locais o papel de salvar suas economias locais - como autor diz, o capitalismo local. A conjuntura, portanto, dá poder e centralidade ao Estado, diferindo da tendência propagada pela ideologia liberal que o mundo vinha encarando de diminuir o poder e importância dos Estados em função dos mercados, estes cada vez menos nacionais.

Referindo-se à França, o autor destaca que não faz sentido culpabilizar somente o atual presidente Macron, pois para ele a culpa cairia, nesse âmbito, nos governantes dos últimos 30 anos, pelo menos. Ressalta que ambos os lados do espectro político francês e cita para isso os "politicamente corretos" e os defensores de um "nacionalismo repugnante" - esperam nos bastidores prosperar politicamente a partir da pandemia. Ainda, o autor destaca a oportunidade do isolamento e do "interlúdio epidêmico" para pensar novos projetos políticas e novas figuras públicas, chegando até mesmo a citar o progresso de uma terceira fase do comunismo. No entanto, não enxerga nenhuma mudança real no horizonte das condições políticas da França. Deixa claro, portanto, a sua lição: "a epidemia em curso não terá, de forma alguma, consequências políticas dignas de nota num país como a França" (p. 41).

\section{Um golpe como o de "kill bill” no capitalismo, por Slavoj Žižek}

Ao abordar a crise epidêmica causada pelo coronavírus, o filósofo esloveno Slavoj Žižek prefere fazer uma reflexão a partir de outro vírus que também foi desencadeado: o vírus ideológico. Em princípio, há o aumento do número de fake news, ataques racistas e novas teorias da conspiração; no entanto, o vírus ideológico não traz apenas malefícios, já que nos faz pensar na sociedade no qual estamos inseridos. $O$ autor procura fazer esta reflexão após especulações de que os transtornos causados pelo coronavírus provocariam a queda do comunismo chinês, quando, na verdade, as especulações deveriam estar em torno de uma sociedade global alternativa onde a solidariedade prevalece.

Para explicitar tal pensamento, Žižek relembra da "técnica dos cinco pontos para explodir um coração", o ataque mitológico - e mais mortal - das artes marciais que se encontra na obra cinematográfica "Kill Bill: Volume 2", de Quentin Tarantino (2004). O golpe, após a combinação de cinco movimentos, faz com que uma pessoa exploda o coração de seu inimigo após o mesmo dar cinco passos, ou seja, ele pode manter uma conversa e ao 
mesmo tempo ter conhecimento de sua morte. Para o autor, a técnica é semelhante às especulações sobre a queda do governo chinês: "as autoridades podem sentar-se, observar e lidar com formalidades como quarentenas, mas qualquer mudança real na ordem social (como confiar nas pessoas) resultará na sua ruína" (p. 44). Todavia, a opinião mais radical do autor analisa o destino do golpe sendo o sistema capitalista.

O autor usa mais uma vez de metáforas envolvendo filmes, dessa vez os catastróficos, para mostrar que só há cooperação entre sociedades quando o mundo está em ameaça. Agora que isto é real é preciso repensar a sociedade em que vivemos, pois, "a resposta adequada não é o pânico, mas sim a ação urgente de estabelecer algum tipo de coordenação global e eficiente" (p. 45). Assim, o autor aborda a volta de mais um fenômeno, o animismo capitalista, que ao tratar do capital financeiro como um organismo vivo deslegitima todas as mortes que estão ocorrendo. Dessa forma, fica claro que é preciso enxergar alguns efeitos benéficos da epidemia e falar disso não é promover ideais comunistas para as sociedades, mas retomar a necessidade em regularizar o mercado mundial e limitar a soberania dos Estados porque "a primeira coisa que devemos aceitar é que a ameaça está aqui para ficar" (p. 46). Então, quando o modelo econômico vigente entra em colapso uma solução em conjunto deve ser tomada, mesmo que esta seja radical.

\section{Conclusão}

Dentre os autores: filósofos, sociólogos, geógrafos, historiadores e jornalistas, há um fio que une os artigos: a pandemia expõe as consequências mais nefastas do neoliberalismo e seus efeitos na saúde pública e na política. Os autores destacam como a lógica capitalista é insustentável na saúde pública, provavelmente de maneira mais explícita do que em outras áreas, ainda mais em momentos catastróficos. Mike Davis destaca que mesmo após variados surtos de doenças como Ebola, SARS, gripe suína, etc. e até mesmo Hollywood explorar o tema, as políticas de austeridade reduziram os investimentos em emergência médica e saúde pública em geral nos Estados Unidos, o que deixa o país em situação de despreparo frente ao eminente coronavírus. Este legado das políticas neoliberais também foi observado por Alain Bihr na França e é uma constante na maioria das democracias liberais. Quanto às consequências políticas mais diretas do coronavírus, Alain Badiou é pessimista a curto prazo, mas constata que o momento clama por reflexão e por renovação. De maneira geral, os autores propõem soluções para a mudança do sistema econômico atual, estas sendo mais orientadas para ações socialistas.

Quanto à forma dos artigos, destacamos a inventividade do filósofo Žižek por ter escrito um artigo utilizando o cinema como metáfora para descrever como a crise do coronavírus pode afetar o sistema capitalista. O tamanho reduzido dos artigos - e, portanto, do livro (são apenas 48 páginas) - não permite que os autores aprofundem seus argumentos e temas. Com o termo "luta de classes" no título, sentimos falta de uma discussão mais ampla acerca do impacto do coronavírus sobre as populações mais vulneráveis e/ou mesmo da tensão entre as classes e suas distintas respostas à crise, ainda que Zibechi escreva brevemente sobre os efeitos da quarentena na paisagem das cidades. Nesse sentido, podemos afirmar que a obra servirá de ponto de partida para esforços mais abrangentes e aprofundados, amadurecidos pelos acontecimentos políticos, econômicos e da saúde pública frutos da pandemia. 
Coronavírus e a luta de classes é um dos primeiros esforços a pensar criticamente a pandemia do coronavírus. Destarte, há de se elogiar o pioneirismo da obra, pois essa importante contribuição certamente inspirará outros trabalhos. E que esses trabalhos busquem uma alternativa de reorganização econômica na qual o fator humano seja o determinante, não um número, uma cifra.

\section{NOTAS}

1. Consultar: https://g1.globo.com/bemestar/coronavirus/noticia/2020/04/11/coronavirus-emais-letal-entre-negros-no-brasil-apontam-dados-do-ministerio-da-saude.ghtml. Acesso em: 16 de abril de 2020.

2. Consultar: https://internacional.estadao.com.br/noticias/geral,governos-buscam-caminhospara-sair-da-quarentena-sem-provocar-novo-surto,70003267876. Acesso em: 16 de abril de 2020.

3. Consultar: https://g1.globo.com/economia/noticia/2020/02/27/saude-deixou-de-receber-r-9bi-em-2019-devido-a-regra-do-teto-de-gastos-mostra-tesouro-nacional.ghtml. Acesso em: 16 de abril de 2020.

\section{AUTORES}

\section{BRUNA SOLOINA MONTEIRO MACHADO}

Graduanda em Geografia pela Universidade Federal Rural do Rio de Janeiro - UFRRJ. Bolsista PIBIC-CNPq. Integrante do Grupo de Pesquisa Reestruturação Econômico-Espacial Contemporânea, do Laboratório de Geografia Política e Econômica da UFRRJ. E-mail: brunamsoloina@gmail.com.

\section{MARCOS VINÍCIUS FERNANDES GONÇALVES}

Graduando em Geografia pela Universidade Federal Rural do Rio de Janeiro - UFRRJ. Bolsista PIBIC-CNPq. Integrante do Laboratório Política, Epistemologia e História da Geografia. E-mail: marcos.v.8@hotmail.com.

\section{MARIA FERNANDA GOMES ARCANJO}

Graduanda em Relações Internacionais pela Universidade Federal Rural do Rio de Janeiro UFRRJ. Bolsista PIBIC-CNPq. Integrante do Grupo de Pesquisa Reestruturação Econômico-Espacial Contemporânea, do Laboratório de Geografia Política e Econômica da UFRRJ. E-mail: xmarifernanda@gmail.com 